\title{
ILHAS DE CALOR URBANAS: MÉTODOS E TÉCNICAS DE ANÁLISE
}

AMORIM, Margarete Cristiane de Costa Trindade - margarete.amorim@unesp.br Universidade Estadual Paulista / UNESP - Campus de Presidente Prudente

RESUMO: Para refletir sobre o tema proposto na mesa do XIII Simpósio Brasileiro de Climatologia Geográfica, intitulada "Climatologia urbana metodologias e técnicas: alterações climáticas, sustentabilidade e resiliência", alguns recortes foram necessários, considerando-se a amplitude e complexidade que o envolve. Desta forma, este texto versará sobre metodologias e técnicas utilizadas nos estudos das ilhas de calor em cidades de médio e de pequeno porte, tendo-se como objetivos: apresentar os conceitos e tipos de ilhas de calor urbanas; refletir sobre a construção teórica e metodológica que tem direcionado os estudos de clima urbano realizados em cidades de pequeno e médio porte; evidenciar as principais técnicas e procedimentos utilizados para o diagnóstico das ilhas de calor da atmosfera inferior; e abordar formas de representação espacial e temporal das intensidades das ilhas de calor da atmosfera inferior e relacioná-la com as ilhas de calor superficiais. Por meio de alguns exemplos, buscou-se mostrar os avanços do conhecimento na climatologia urbana, principalmente quando se trata da geração das ilhas de calor nas suas diferentes formas de manifestações e representações. Acredita-se que o detalhamento das ilhas de calor urbanas possibilita o oferecimento de subsídios à gestão territorial e ao planejamento urbano, visando a sustentabilidade da sociedade, para que seja possível a construção de cidades mais saudáveis para seus habitantes.

PALAVRAS-CHAVES: clima urbano, ilha de calor urbana, cidades de pequeno e médio porte.

\section{URBAN HEAT ISLANDS: ANALYSIS METHODS AND TECHNIQUES}

ABSTRACT: In order to reflect on the subject proposed in the 13th Brazilian Symposium on Geophysical Climatology, entitled "Urban climatology methodologies and techniques: climate change, sustainability and resilience," some highlights were necessary, considering the broad scope and complexity involved. Thus, this text addresses methodologies and techniques used in the study of heat islands in small and mediumsized cities, with the following purposes: to present the concepts and types of urban heat islands; to reflect on the theoretical and methodological construction that has guide urban climate studies carried out in small and medium-sized cities; to demonstrate the main techniques and procedures used for the diagnosis of heat islands in the lower atmosphere; and to address forms of spatial and temporal representation of the intensities of heat islands in the lower atmosphere and relate them to the surface heat islands. By means of some examples, this study aimed to show the advances of the knowledge in urban climatology, mainly regarding the generation of heat islands in their different forms of manifestations and representations. It is believed that the detailing of urban heat islands makes it possible to offer support to territorial management and urban planning, aiming at the sustainability of society, so that it is possible to build healthier cities for its inhabitants.

KEYWORDS: urban climate, urban heat islands, small and medium-sized cities.

\section{INTRODUÇÃO}

O interesse pelos estudos do clima urbano tem aumentado não apenas porque a maior parte da população brasileira e mundial vive nas cidades, mas também pelo processo de degradação desses ambientes e seus efeitos na qualidade de vida dos citadinos.

A matriz teórica e metodológica que direciona o pensamento na grande maioria das pesquisas realizadas no Brasil, tem como referência a obra de Monteiro (1976), que sistematizou a proposta do Sistema Clima Urbano. 
Neste texto, com o objetivo de refletir sobre o tema proposto na mesa do XIII Simpósio Brasileiro de Climatologia Geográfica, intitulada "Climatologia urbana metodologias e técnicas: alterações climáticas, sustentabilidade e resiliência", alguns recortes foram necessários, considerando-se a amplitude e complexidade que o envolve, assim como algumas das experiências acumuladas em quase 20 anos de pesquisa junto ao grupo GAIA ${ }^{1}$. Tais experiências referemse às metodologias e técnicas utilizadas nos estudos das ilhas de calor em cidades de médio e de pequeno porte.

Antes de adentrar neste tema central serão apresentados alguns argumentos que justificam a opção pelos estudos em cidades de médio e de pequeno porte.

É evidente que os problemas relacionados ao clima urbano, tais como a geração das ilhas de calor, aos impactos deflagrados por eventos de precipitação ou dos problemas decorrentes da poluição atmosférica são mais visíveis e percebidos pela população nas grandes aglomerações urbanas.

Entretanto, nos diversos estudos realizados na climatologia brasileira, e em nível internacional, tem se verificado que assim como nos grandes centros urbanos, as cidades de médio e de pequeno porte, também passaram por fortes transformações na paisagem natural, materializadas através de diferentes formas de poluição do ar, água, solo e subsolo, além de transformações na morfologia e estrutura do ambiente urbano. Rios e córregos são canalizados ou têm seus cursos alterados; a morfologia é modificada através de aterros e construções; a vegetação é retirada. Além disso, a associação das atividades urbanas com a forma de ocupação da terra provoca alterações nos processos dinâmicos da atmosfera e, consequentemente, nos elementos climáticos (AMORIM, 2017).

Outros aspectos a serem considerados na opção pelas cidades médias e pequenas, se referem a importância que possuem na economia nacional e também porque nelas vive a maioria da população brasileira. Conforme as informações apresentadas por Motta e Mata (2008, p. 33), somando-se o percentual da população nos municípios de pequeno e médio porte, este atingia $70,75 \%$ do total nacional, sendo $24,36 \%$ em municípios entre 100 e 500 mil habitantes e $46,39 \%$ em municípios menores do que 100 mil habitantes. No censo demográfico do IBGE (2010), a participação de tais municípios na população nacional atingiu o total de 106.568 .177 habitantes $(66 \%)$, sendo 43.992.408 (27,34\%) em municípios entre 100 mil e 500 mil habitantes e 62.575 .769 (38,88\%) em municípios menores do que 100 mil habitantes.

Além disso, em 2005, possuíam 58,06\% de participação no produto interno bruto (PIB) nacional. Segundo Motta e Mata (2008), desde a década de 1970, as cidades médias têm desempenhado um papel importante na dinâmica econômica e espacial do país.

Há, portanto, expressiva quantidade de pessoas que vivem nos centros urbanos de pequeno e médio porte e, consequentemente, são afetadas por suas

\footnotetext{
${ }^{1}$ GAIA - grupo de pesquisa "Interações na superfície terrestre, água e atmosfera" cadastrado no CNPq, desde 2002 e, atualmente, liderado por Margarete Cristiane de Costa Trindade Amorim e João Osvaldo Rodrigues Nunes, com sede na Universidade Estadual Paulista (UNESP), Faculdade de Ciências e Tecnologia, campus de Presidente Prudente/SP.
} Ano 15 - Edição Especial - XIII Simpósio Brasileiro de Climatologia Geográfica - JUN 2019 
características específicas, particularmente no que diz respeito às alterações na atmosfera e na geração das ilhas de calor urbanas.

Cabe destacar que os rigores das altas temperaturas, especialmente nas áreas de clima tropical continental, naturalmente propiciam desconforto térmico para a população, que são acentuados pelas ilhas de calor. Além disso, intensidades de temperaturas diferenciadas entre as áreas construídas e não construídas propiciam movimentos advectivos do ar, contribuindo para o transporte de poluentes atmosféricos e de materiais particulados para as áreas mais quentes e densamente edificadas, onde se encontra a maioria da população.

Este fato pode contribuir para o aumento de problemas respiratórios, típicos da estação seca de grande parte do território nacional. Deste modo, as ilhas de calor além de afetarem diretamente o conforto dos indivíduos contribuem para o aumento de doenças relacionadas à qualidade do ar.

A partir dessas justificativas, para o estudo das ilhas de calor em cidades de médio e de pequeno porte, este texto tem como objetivo apresentar os conceitos e tipos de ilhas de calor urbanas; refletir sobre a construção teórica e metodológica que tem direcionado os estudos de clima urbano realizados em cidades de pequeno e médio porte; evidenciar as principais técnicas e procedimentos utilizados para o diagnóstico das ilhas de calor da atmosfera inferior; e abordar formas de representação espacial e temporal das intensidades das ilhas de calor da atmosfera inferior e relacioná-la com as ilhas de calor superficiais.

\section{AS ILHAS DE CALOR URBANAS: CONTEXTO, CONCEITO E TIPOS}

As maiores temperaturas nas cidades em relação aos registros rurais foram mostradas em vários estudos, sendo o primeiro deles publicado em 1818 (primeira edição) por Luke Howard (e em uma segunda edição em $1833^{2}$ ).

A partir deles, muitos outros estudos foram feitos, inicialmente nas cidades de latitudes médias (CHANDLER, 1965; LANDSBERG, 1970; OKE, 1978; MONTEIRO, 1997); e mais recentemente no ambiente tropical, destacando-se neste texto aqueles realizados no Brasil (TARIFA, 1977; SARTORI, 1979; LOMBARDO, 1985; ASSIS, 1990; MAITELLI, 1994; ZAMPARONI, 1995; BRANDÃO, 1996; TAVARES, 1997; VECCHIA, 1997; FONZAR, 1981; SAMPAIO, 1981; DANNI-OLIVEIRA, 1987; MENDONÇA, 1994; SANTOS, 1996; SETTE, 1996; SOUZA, 1996; PITTON, 1997; AMORIM, 2000, 2017; SOUZA et al., 2010; RAMPAZZO, 2012; AL MANNE， 2014; TEIXEIRA， 2015; DORIGON, 2015; CARDOSO, 2015; MENDONÇA，2015; PORANGABA，2015; RAMPAZZO， 2015; NAKATA-OSAKI et al., 2016; dentre outros).

As paisagens naturais sofreram, no decorrer do tempo, muitas transformações. Entretanto, os efeitos do ar comprometido no urbano produzem alterações nos elementos climáticos de maneira mais intensa, quando se compara ao ambiente rural.

\footnotetext{
${ }^{2}$ Esta obra está disponível no endereço: http://www.urban-climate.org/documents/LukeHoward_Climate-ofLondon-V1.pdf Ano 15 - Edição Especial - XIII Simpósio Brasileiro de Climatologia Geográfica - JUN 2019
} 
Como não é possível se avaliar as modificações nos elementos do clima desde o início da presença das pessoas, seja no campo ou na cidade, pelo simples fato de que não há registros sistemáticos de tais elementos, a principal referência para se avaliar a interferência das cidades na geração de um clima propriamente urbano é a comparação com o entorno rural próximo, considerado menos alterado em relação à paisagem original do que as cidades (AMORIM, 2017).

Oke (1978) mostrou que a característica mais importante da ilha de calor atmosférica é sua intensidade, entendida como a diferença entre o máximo da temperatura urbana e o mínimo da temperatura rural no mesmo instante.

Nesta mesma perspectiva, Fernández García (1996), definiu a intensidade e a magnitude das ilhas de calor considerando-se as diferenças térmicas entre o rural e o urbano registradas por meio dos seguintes parâmetros: ilha de calor de fraca magnitude, quando as diferenças entre os pontos mais quentes e mais frios variam de $0^{\circ} \mathrm{C}$ a $2^{\circ} \mathrm{C}$; de média magnitude, quando variam de $2^{\circ} \mathrm{C}$ a $4^{\circ} \mathrm{C}$; de forte magnitude quando variam de $4^{\circ} \mathrm{C}$ a $6{ }^{\circ} \mathrm{C}$; e de muito forte quando superiores a $6^{\circ} \mathrm{C}$.

Deste modo, as análises das intensidades e magnitudes das ilhas de calor, permitem estudos comparativos entre diferentes cidades em contextos climáticos variados (AMORIM e DUBREUIL, 2017).

As ilhas de calor atmosféricas são, portanto, definidas como bolsões de ar quente registrados nos ambientes urbanos decorrentes da capacidade diferenciada dos materiais encontrados na superfície de armazenar e refletir a energia solar e da produção do calor antropogênico. Resultam das diferenças no balanço de energia entre a área urbana e rural, além das diferenças existentes no interior da própria cidade (AMORIM, 2017).

Oke (1982, p. 7) considerou a ilha de calor como sendo uma anomalia térmica com dimensões horizontais, verticais e temporais, observada na maioria dos locais onde os estudos foram realizados. Ela é calculada considerando-se a diferença da temperatura, registrada simultaneamente, entre o ambiente construído e o não construído $(\Delta T u-r)$.

A literatura aponta três principais tipos de ilhas de calor urbanas em função da camada onde são encontradas: 1 - a ilha de calor superficial diagnosticada por meio do sensoriamento remoto, que permite o cálculo da temperatura dos alvos (OKE et al., 2017); 2 - a ilha de calor atmosférica inferior, que Oke (1978) denominou urban canopy layer, cuja temperatura é registrada entre o nível do solo e o nível médio dos telhados. Neste caso, as temperaturas são medidas abaixo do nível do topo dos edifícios, por meio de diferentes procedimentos, tais como, transectos móveis (medidas itinerantes com veículos) e pontos fixos por meio de uma rede de sensores de temperatura inseridos na malha urbana e no ambiente rural; 3 - a ilha de calor da atmosfera urbana superior, denominada por Oke (1978) urban boundary layer. Esta se sobrepõe à anterior e se estende por vezes até à atmosfera livre.

Assim, os principais fatores que contribuem à formação das ilhas de calor urbanas resultam do balanço de energia que é consequência dos aspectos naturais e urbanos. Dentre os fatores naturais destacam-se os tipos de tempo, o relevo e a presença/ausência de superfícies com vegetação e dos fatores urbanos, as características dos espaços construídos e as atividades humanas. 


\section{O OLHAR PARA A CIDADE: A CONSTRUÇÃo TEÓRICA E METODOLÓGICA NOS ESTUDOS DAS ILHAS DE CALOR}

A principal referência teórica e metodológica utilizada no Brasil para os estudos de clima urbano é a consagrada obra do Prof. Dr. Carlos Augusto de Figueiredo Monteiro, intitulada "Sistema Clima Urbano" (MONTEIRO, 1976).

No Sistema Clima Urbano (SCU), a cidade é investigada sob uma perspectiva integradora que propõe adotar uma concepção dinâmica dirigida pelo paradigma do ritmo de sucessão habitual dos estados atmosféricos sobre as cidades e buscar a mensuração do ar comprometido dentro da realidade do ambiente urbano (MONTEIRO, 1976), diferenciando-se, portanto, dos propósitos puramente meteorológicos predominantes nos clássicos da literatura internacional (OKE, 1978; BRYSON, 1972; CHANDLER, 1965; LANDSBERG, 1981; LOWRY, 1977; dentre outros).

Esta perspectiva integradora fundamentou-se na abordagem sistêmica e o clima urbano foi definido como "um sistema que abrange o clima de um dado espaço terrestre e sua urbanização" (MONTEIRO, 1976, p. 95). Para tais estudos, o autor sugeriu a adoção de três subsistemas: o termodinâmico, o físico-químico e o hidrometeórico. Para esta organização teve como referência os canais de percepção humana, ou seja, buscou sistematizar certas características presentes na atmosfera e que interferem na vida cotidiana das pessoas (conforto térmico, qualidade do ar e meteoros de impactos).

A partir desta proposta e buscando compreender os aspectos estruturais na geração do clima urbano e das ilhas de calor, Sant'Anna Neto (2012), aponta a necessidade de se avançar e enriquecer as análises incorporando-se a dimensão social na interpretação do clima urbano. Esta perspectiva pressupõe que a compreensão da repercussão dos fenômenos atmosféricos na superfície terrestre ocorre em um território, transformado e produzido pela sociedade, de maneira desigual e apropriado conforme os interesses dos agentes sociais.

\footnotetext{
Se o espaço geográfico é produzido de forma altamente complexa e fortemente desigual. Se o clima é o produto da interação entre os processos dinâmicos da atmosfera e das ações dos agentes sociais, que ao produzirem novas territorialidades modificam as características fundamentais dos elementos climáticos. Então os diversos grupos sociais não experimentam nem percebem o tempo e o clima da mesma forma. Espaços desiguais potencializam efeitos do clima, igualmente desiguais. Nesta perspectiva temos que admitir que o clima é uma construção social (SANT'ANNA NETO, 2012, p. 35-36).
}

Nos últimos anos investiu-se no delineamento de um conjunto de procedimentos metodológicos (AMORIM 2000; 2005; 2010; 2014; 2017 e AMORIM ET AL. 2009; 2015) para não apenas registrar e diagnosticar as ilhas de calor, mas também para apresentar os resultados, seja do ponto de vista espacial, como também temporal, mostrando sua evolução diária sob tipos de tempo predominantes nas estações seca e chuvosa.

Os resultados das pesquisas tem demonstrado que a produção das ilhas de calor se manifesta, por um lado, pelas modificações nas características da superfície e, por outro, pelas atividades desenvolvidas pela sociedade. Tudo isto em função das formas de apropriação e da expansão territorial urbana, ou seja, 
pelas decisões tomadas pelos sujeitos sociais protagonistas do processo de produção do espaço.

O clima urbano resulta, portanto, das características da dinâmica da atmosfera atrelada com o uso e ocupação da terra que dependem da maneira como o espaço é produzido, tendo-se como referências as dinâmicas econômicas e sociais inerentes a cada núcleo urbano.

Os elementos do clima são modificados tanto por características naturais quanto pela urbanização e os produtos decorrentes são: a geração das ilhas de calor e das ilhas secas, o desconforto térmico, as inversões térmicas, as inundações e alagamentos, a chuva ácida e a poluição do ar (MONTEIRO, 1976).

\section{A ESPACIALIZAÇÃO DA EVOLUÇÃO DIÁRIA DAS ILHAS DE CALOR DA ATMOSFERA INFERIOR}

A espacialização da intensidade das ilhas de calor é um problema recorrente na climatologia porque resulta na criação de um campo contínuo a partir de observações individuais (pontos) por meio da interpolação espacial. Segundo Foissard (2015), tais interpolações podem se processar por dois grupos de métodos: os métodos geoestatísticos e os métodos multicritérios.

A interpolação pela geoestatística ocorre com base no princípio da auto correlação espacial, ou seja, a semelhança de um ponto com seu entorno próximo. Esse método tem recebido várias críticas porque a interpolação de dados é uma abstração da realidade, na medida em que se afasta do ponto de observação e os resultados serão mais ou menos próximos à realidade em função da densidade da malha de registro de dados e sua distribuição espacial, das características das unidades do relevo e do método utilizado para interpolar (AMORIM, 2017).

O método mais comum para a interpolação é a krigagem e é muito utilizado quando as variáveis oscilam ligeiramente em curtas distâncias. Entretanto, possui limitações quando a variabilidade espacial do fenômeno é menor do que a distância entre os pontos de medição, sendo necessária a multiplicação de pontos de registros (FOISSARD, 2015; AMORIM et al., 2015).

Nos métodos multicritérios de espacialização dos elementos do clima são considerados ao mesmo tempo diversos fatores que interferem na sua distribuição espacial. Deste modo, ele é mais adequado para o estudo do clima em escalas finas, na medida em que é possível se considerar na espacialização dos elementos do clima, e particularmente no estudo das ilhas de calor urbanas, as características da cobertura da terra, do relevo, da presença de vegetação, dentre outros fatores (AMORIM et al., 2015; AMORIM, 2017).

A modelagem espacial das ilhas de calor permite a análise da distribuição da temperatura no intraurbano e rural próximo para além do que foi registrado nos pontos, na medida em que estima a intensidade da temperatura nos pixels com as mesmas características de onde elas foram registradas considerando-se o uso da terra, a vegetação e o relevo.

A modelagem espacial das ilhas de calor oferece um avanço significativo em relação às formas tradicionais de representações cartográficas por meio de interpolações. As interpolações das temperaturas do ar, embora muito úteis do 
ponto de vista da visualização de sua distribuição espacial, não levam em consideração as características dos alvos superficiais e do relevo e produzem resultados que dificultam intervenções mais localizadas (AMORIM et al., 2015).

A estimativa da temperatura do ar usando imagens de satélite foi utilizada por Kawashima et al. (2000) e, embora seu estudo não tenha sido realizado na escala urbana e sim contemplando uma área de $200 \mathrm{~km} \mathrm{X} 200 \mathrm{~km}$, foram obtidos melhores resultados do que por meio de interpolações espaciais.

A modelagem espacial da intensidade da temperatura do ar, considerando o método multicritério, quando realizada para a análise da evolução diária da ilha de calor atmosférica inferior nos diferentes períodos e estações do ano, permite o detalhamento no intraurbano e rural próximo, podendo ser um importante instrumento para a tomada de medidas mitigadoras para a amenização das ilhas de calor.

Para a elaboração de tais mapas, além das medidas de temperatura do ar no intraurbano e rural próximo, por meio de pontos fixos ou transectos móveis (medidas itinerantes), selecionando-se os pontos de medidas a partir da diversidade de uso e cobertura da terra e características do relevo, seguido do cálculo da intensidade das ilhas de calor $^{3}$, são tratadas as imagens do satélite Landsat 8, conforme descrito a seguir.

Inicialmente elabora-se o mapa de uso da terra a partir de classificação da imagem Landsat 8 (bandas 3, 5 e 4), adquiridas gratuitamente no site http://earthexplorer.usgs.gov/, cujas aplicações são apresentadas na Tabela 1.

Tabela 1 - Intervalo espectral e aplicações das bandas 3, 5 e 4 do satélite Landsat 8

\begin{tabular}{|c|c|c|}
\hline Banda & $\begin{array}{l}\text { Intervalo } \\
\text { espectral }\end{array}$ & Aplicações \\
\hline 3 - Green & $0.53-0.59 \mu \mathrm{m}$ & $\begin{array}{c}\text { Evidencia a vegetação para a avaliação do vigor } \\
\text { das plantas }\end{array}$ \\
\hline $\begin{array}{l}5-\text { Near } \\
\text { Infrared }\end{array}$ & $0.85-0.88 \mu \mathrm{m}$ & Evidencia o teor de biomassa \\
\hline 4 - Red & $0.64-0.67 \mu \mathrm{m}$ & $\begin{array}{l}\text { Discrimina a vegetação em função do conteúdo em } \\
\text { clorofila }\end{array}$ \\
\hline
\end{tabular}

Fonte: http://landsat.usgs.gov/best_spectral_bands_to_use.php

As três bandas possibilitam a geração de um mapa de composição colorida que diferencia as áreas urbanas e rurais e, juntamente com trabalhos de campo e conhecimento do terreno, viabilizam a classificação do uso da terra.

Utilizando-se das bandas 3, 5, e 4 do Landsat 8 e da carta de NDVI se processa a classificação automática do uso da terra por Cluster (classificação não supervisionada).

Para a elaboração do mapa do Índice de Vegetação por Diferença Normalizada (NDVI - Normalized Difference Vegetation Index), parte-se do cálculo da razão normalizada entre as bandas do infravermelho próximo e a

\footnotetext{
${ }^{3}$ Para o cálculo da intensidade das ilhas de calor, define-se o ponto "0" de referência (local onde habitualmente se registra a menor temperatura do ar) e, a partir dele, se processa o cálculo da intensidade da temperatura do ar dos outros pontos, subtraindo-se o valor medido em cada ponto $(\Delta T u-r)$.
}

Ano 15 - Edição Especial - XIII Simpósio Brasileiro de Climatologia Geográfica - JUN 2019 
banda do vermelho (junção das bandas 4 e 5 do satélite Landsat 8). A escala gerada nesta carta (entre -1 e +1 ) permite diferenciar as áreas urbanas (construções e arruamentos), nos valores menores, das que possuem vegetação com densidades variadas (alta, média e baixa), nos valores maiores. Assim, considerando-se a escala gerada nos mapas do NDVI, quanto mais próxima de +1 , maior a densidade vegetal e quanto mais próxima de -1 , menor sua densidade.

Com base na classificação inicial não supervisionada se realiza o agrupamento das classes tendo-se como referência a carta de composição colorida, a carta de NDVI e do conhecimento de campo. A classificação final pode se reduzir a três classes, sendo elas as construções, a vegetação rasteira e a vegetação densa, de acordo com o elemento que predomina em cada pixel.

Assim, como em Amorim et al. (2015), a classe "vegetação densa" reúne as áreas com cobertura vegetal arbórea presentes nas áreas verdes urbana, nos parques e nos fundos de vale. A "vegetação rasteira" considera as pastagens do rural próximo, os terrenos urbanos sem construções, mas com presença de gramados. A classe "construções" agrupa todas as áreas impermeabilizadas tanto com alta, média e baixa densidade de construções como as vias pavimentadas.

$\mathrm{Na}$ sequência calcula-se o centro geométrico para se considerar a distância do centro no resultado final da modelagem.

A distância do centro é calculada a partir de polígono que indica o centro densamente construído da malha urbana. Este procedimento permite definir estatisticamente a representatividade da localização dos sensores de temperatura.

Para a análise da relação entre a temperatura do ar e o uso da terra, inicialmente calcula-se quantos pixels de cada classe estão no entorno de onde foram realizados os registros das temperaturas. Assim, chega-se "à correlação entre a temperatura do ar medida e a frequência de cada classe de uso da terra em janelas móveis de tamanho variável entre $3 \times 3$ pixels ( $90 \times 90$ metros), $5 \times 5$ pixels $(150 \times 150$ metros $)$ e de $9 \times 9$ pixels $(270 \times 270$ metros $)$ e assim por diante, considerando que a resolução espacial do Landsat 8 nas bandas selecionadas é de 30 metros. Esse procedimento é fundamental porque não se sabe inicialmente qual a área de influência do uso da terra sobre as medidas de temperatura para cada ponto e isso justifica o teste com essas janelas de tamanho 'móveis'" (AMORIM et al., 2015; GOMES et al., 2017; PORANGABA, et al., 2017; TEIXEIRA e AMORIM, 2017).

Além do uso da terra (construções, vegetação rasteira e vegetação densa), também é importante se incorporar na modelagem informações sobre o relevo. Sabe-se que o relevo é um importante fator do clima que interfere na distribuição da temperatura do ar. Deste modo, para incorporá-lo na modelagem, buscou-se a hipsometria da área escolhida para este texto (Presidente Prudente e rural próxima) no site http://www.webmapit.com.br/inpe/topodata.

Com todas essas informações (uso da terra, hipsometria, distância do centro e NDVI) são feitas relações estatísticas e regressão múltipla entre a intensidade da ilha de calor atmosférica nos locais onde as temperaturas são registradas e os parâmetros geográficos da superfície. O modelo discrimina os 
melhores indicadores espaciais para cada categoria de forma a estimar os resultados para toda a imagem através de regressão linear múltipla.

Assim, a construção do modelo espacial por meio da regressão linear múltipla permite a correlação entre as variáveis geográficas (uso da terra, hipsometria, distância do centro e NDVI) e o elemento do clima em análise: a intensidade da temperatura. O detalhamento desses procedimentos pode ser consultado em (AMORIM et al., 2015; GOMES et al., 2017; PORANGABA, et al., 2017; TEIXEIRA E AMORIM, 2017).

A título de exemplo será apresentada no próximo item a evolução diária da ilha de calor atmosférica, tendo-se como referência o trabalho apresentado por Amorim (2017).

\section{EXEMPLO DA EVOLUÇÃo DIÁRIA DA ILHA DE CALOR DA ATMOSFERA INFERIOR E SUAS RELAÇÕES COM A ILHA DE CALOR SUPERFICIAL}

O exemplo a seguir mostra a evolução diária da intensidade da ilha de calor em Presidente Prudente (Figura 1) no dia 08/06/2015, nos horários selecionados de $0 \mathrm{~h}, 3 \mathrm{~h}, 6 \mathrm{~h}, 9 \mathrm{~h}, 12 \mathrm{~h}, 15 \mathrm{~h}, 18 \mathrm{~h}$ e $21 \mathrm{~h}$, representativos dos períodos do dia (manhã, tarde e noite). Neste dia foram registrados os dados das temperaturas ${ }^{4}$ horárias em 26 pontos do intraurbano e entorno rural próximo de Presidente Prudente, coincidindo com a passagem do satélite Landsat 8 às $10 \mathrm{~h} 22$ (hora local).

Por meio dos procedimentos anteriormente apresentados chegou-se às melhores correlações estatísticas entre as classes 1 (construções), 2 (vegetação rasteira) e 3 (vegetação densa) e a intensidade da temperatura do ar no dia de registro e nos horários que serviram de base para a geração dos mapas com as intensidades das temperaturas do ar. Foram colocados sensores em pontos representativos dessas características, com uma rede mais densa no ambiente intraurbano para a obtenção de informações suficientes para a elaboração da modelagem da intensidade da temperatura do ar, levando-se em consideração as características predominantes na superfície (Figura 2).

Na Tabela 2 verifica-se que no período noturno ( $0 \mathrm{~h}, 3 \mathrm{~h}, 6 \mathrm{~h}, 18 \mathrm{~h}$ e $21 \mathrm{~h}$ ), as melhores correlações estatísticas entre as intensidades das temperaturas do ar e a porcentagem do uso da terra ocorreram nas classes 1 e 3, predominantemente nas janelas $33 \times 33$. A maioria delas ficou acima de 0.7 , em uma escala de 0 a 1 . Na classe 2 (vegetação rasteira) as correlações entre as intensidades das temperaturas do ar e a porcentagem desse tipo do uso da terra foram menores, quando se compara com os resultados das classes 1 e 3 , e por este motivo não foi inserida na fórmula final da modelagem.

Os parâmetros foram estatisticamente independentes, ou seja, com correlações baixas entre eles. Assim, apenas as classes de uso da terra "construções" (1) e "vegetação densa" (3) foram utilizadas na modelagem. Os coeficientes da classe 1 "construções" foram positivos (Tabela 2). Na estimativa final, isso evidenciou a importância maior das construções para gerar a ilha de

\footnotetext{
${ }^{4}$ Os equipamentos utilizados no registro de temperatura foram: 20 data logger (U23-002) da marca HOBO, protegido por abrigo da mesma marca do tipo RS3 e 5 estações meteorológicas tipo Vantage PRO 2 da marca Davis Instruments, além da estação meteorológica oficial do Instituto Nacional de Meteorologia.
}

Ano 15 - Edição Especial - XIII Simpósio Brasileiro de Climatologia Geográfica - JUN 2019 
calor urbana e assim modelar a temperatura nessa escala. As classes "vegetação densa" e "vegetação rasteira" tiveram coeficientes negativos, ou seja, evidenciaram o papel da vegetação para reduzir a temperatura.

$\mathrm{Na}$ Tabela 2 também se verifica que no período noturno ( $0 \mathrm{~h}, 3 \mathrm{~h}, 6 \mathrm{~h}, 18 \mathrm{~h}$ e $21 \mathrm{~h})$, quando as ilhas de calor atingiram as maiores magnitudes no dia em análise (08/06/2015), o efeito da vizinhança do uso da terra sobre a temperatura funcionou menos com os pixels próximos e mais dentro de janelas maiores mostrando o efeito global do uso da terra, assim como foi verificado nos trabalhos de Foissard et al. (2013) e Amorim et al. (2015). Isto evidencia que esta metodologia está adequada na escala de estudo das cidades médias e pequenas, minimizando os efeitos microclimáticos e permitindo uma cartografia na escala da aglomeração.

Tabela 2 - Correlações estatísticas entre as intensidades das temperaturas do ar e as construções (classe 1), a vegetação rasteira (classe 2 ) e a vegetação densa (classe 3 )

\begin{tabular}{|c|c|c|c|c|c|c|c|c|}
\hline \multicolumn{9}{|c|}{$08 / 06 / 2015$} \\
\hline Hora & $\mathbf{O h}$ & $3 \mathbf{h}$ & 6h & $9 \mathrm{~h}$ & $12 \mathrm{~h}$ & $15 \mathrm{~h}$ & $18 \mathrm{~h}$ & $21 \mathrm{~h}$ \\
\hline $\begin{array}{c}\text { Classe } 1 \\
\text { Contruções }\end{array}$ & $\begin{array}{l}33 \times 33 \\
0.7248 \\
\end{array}$ & $\begin{array}{r}33 \times 33 \\
0.7969 \\
\end{array}$ & $\begin{array}{l}33 \times 33 \\
0.6967\end{array}$ & $\begin{array}{l}33 \times 33 \\
0.1261 \\
\end{array}$ & $\begin{array}{l}21 \times 21 \\
0.4335\end{array}$ & $\begin{array}{c}9 \times 9 \\
0.6399 \\
\end{array}$ & $\begin{array}{l}33 \times 33 \\
0.8096 \\
\end{array}$ & $\begin{array}{l}33 \times 33 \\
0.8508 \\
\end{array}$ \\
\hline $\begin{array}{c}\text { Classe 2 } \\
\text { Vegetação } \\
\text { rasteira } \\
\end{array}$ & $\begin{array}{r}33 \times 33 \\
-0.2101 \\
\end{array}$ & $\begin{array}{r}33 \times 33 \\
-0.3215 \\
\end{array}$ & $\begin{array}{c}33 \times 33 \\
-0.2047 \\
\end{array}$ & $\begin{array}{r}33 \times 33 \\
-0.0145 \\
\end{array}$ & $\begin{array}{c}17 \times 17 \\
-0.3832 \\
\end{array}$ & $\begin{array}{c}9 \times 9 \\
-0.3947 \\
\end{array}$ & $\begin{array}{r}33 \times 33 \\
-0.3923 \\
\end{array}$ & $\begin{array}{r}33 \times 33 \\
-0.422 \\
\end{array}$ \\
\hline $\begin{array}{c}\text { Classe } 3 \\
\begin{array}{c}\text { Vegetação } \\
\text { densa }\end{array} \\
\end{array}$ & $\begin{array}{c}33 \times 33 \\
-0.8472\end{array}$ & $\begin{array}{r}33 \times 33 \\
-0.8687 \\
\end{array}$ & $\begin{array}{c}33 \times 33 \\
-0.8125\end{array}$ & $\begin{array}{c}33 \times 33 \\
-0.1627 \\
\end{array}$ & $\begin{array}{c}33 \times 33 \\
-0.3238 \\
\end{array}$ & $\begin{array}{c}7 \times 7 \\
-0.5827 \\
\end{array}$ & $\begin{array}{c}29 \times 29 \\
-0.8376 \\
\end{array}$ & $\begin{array}{r}33 \times 33 \\
-0.872\end{array}$ \\
\hline
\end{tabular}

Nos horários diurnos, especialmente às $9 \mathrm{~h}$ e $12 \mathrm{~h}$, foram observadas baixas correlações e, as melhores, foram diagnosticadas, na maioria das vezes, em pixels mais próximos, portanto, em janelas menores sofrendo maior interferência dos efeitos microclimáticos. 


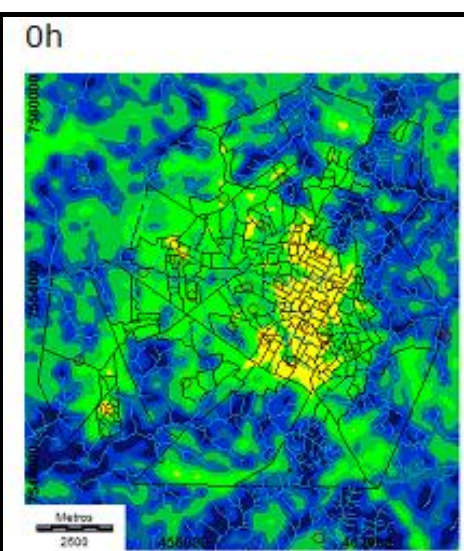

$9 \mathrm{~h}$

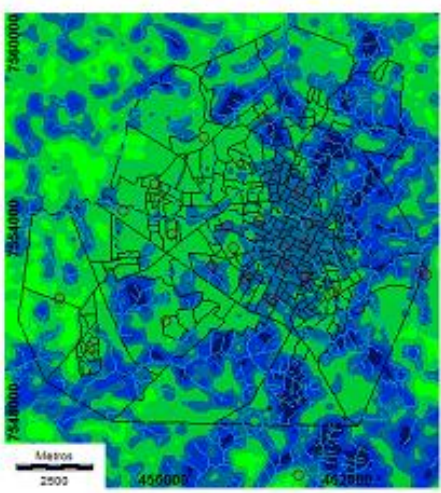

$18 \mathrm{~h}$

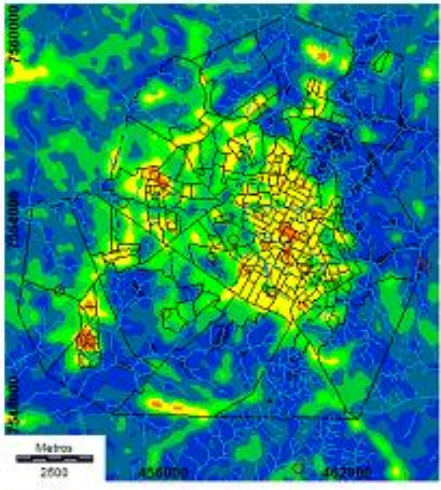

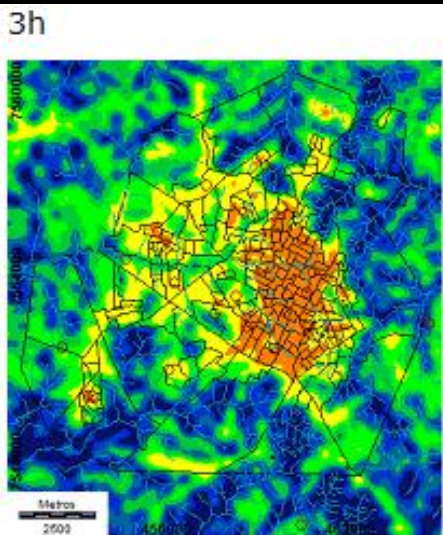

$12 \mathrm{~h}$

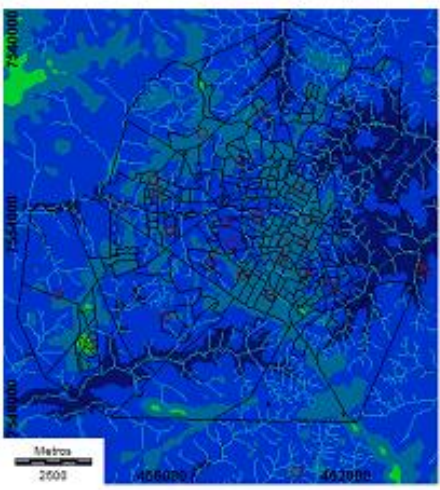

$21 \mathrm{~h}$

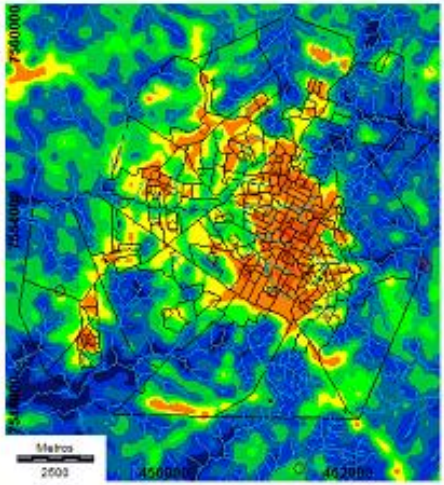

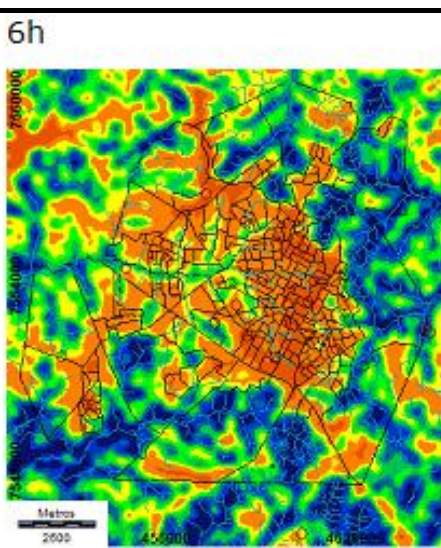

$15 \mathrm{~h}$

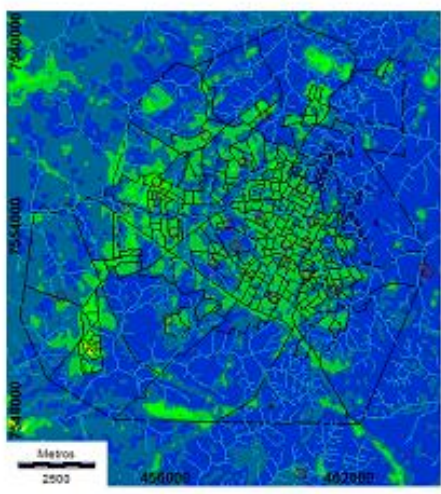

4

$\Delta T$ do ar

$\left({ }^{\circ} \mathrm{C}\right)$

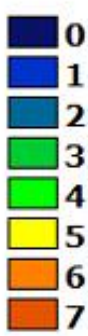

Rede de drenagem

Setor Censitário do IBGE

Localização dos sensores de temperatura<smiles>CCCCCCC</smiles>

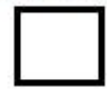

O

Sistem a de Coordenadas Geográficas

Projeção Universal Transversa de Mercator

Datum WGS 84 - 22 Sul

Elaboração: Margarete Amorim

Figura 1 - Presidente Prudente - evolução diária das ilhas de calor atmosféricas $08 / 06 / 2015$ 


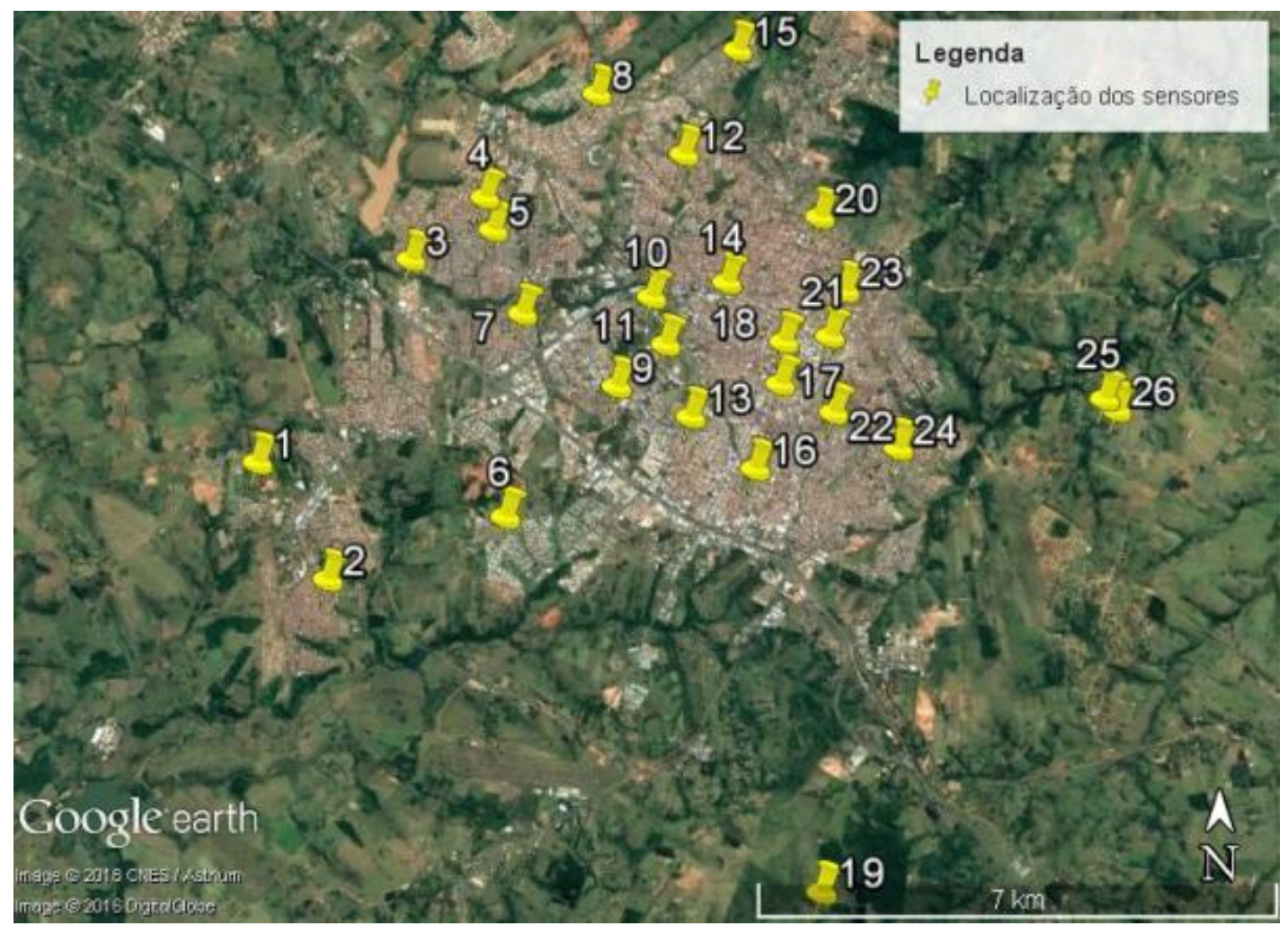

Figura 2 - Presidente Prudente: localização dos sensores de temperatura do ar Fonte: Google Earth TM mapping service/NASA/Terra Métrics copyright (acesso: setembro de 2016).

Para se produzir os mapas de intensidade das temperaturas e diagnosticar a evolução diária das ilhas de calor e onde elas ocorreram (Figura 1), as temperaturas medidas foram generalizadas em cada ponto e se inseriu no modelo, além da intensidade da temperatura do ar nas janelas com as melhores correlações, a distância do centro, os valores da altitude e o NDVI. Assim, as modelagens das intensidades das temperaturas do ar foram generalizadas em cada ponto por meio de regressão linear múltipla e na Tabela 3 são apresentadas as correlações globais.

Tabela 3 - Correlações globais obtidas considerando-se as intensidades das temperaturas do ar, a distância do centro, a altitude e o NDVI resultantes de regressão linear múltipla

\begin{tabular}{ccccccccc}
\hline Hora & Oh & 3h & 6h & 9h & 12h & $\mathbf{1 5 h}$ & $\mathbf{1 8 h}$ & $\mathbf{2 1 h}$ \\
\hline $\mathbf{0 8 / 0 6 / 2 0 1 5}$ & 0.86 & 0.88 & 0.84 & 0.32 & 0.51 & 0.71 & 0.86 & 0.92 \\
\hline
\end{tabular}

\section{AS RELAÇões entre ILHAS de CALOR ATMOSFÉricas E ILHAS DE CALOR SUPERFICIAIS}

A literatura mostra que as temperaturas da superfície têm maior variabilidade espacial e temporal no período diurno do que as temperaturas do ar, devido às características térmicas de diferentes coberturas da terra (BAPTISTA, 2012; GARTLAND， 2010; WENG， 2003; LOMBARDO, 1985; MENDONÇA; DUBREUIL, 2005). 
Todos os objetos que compõem a superfície terrestre são fontes emissoras de radiação eletromagnética com intensidades de emitância proporcionais à sua temperatura de superfície. Como as condições ambientais e climáticas interferem a todo o momento na temperatura de superfície, modificando-a em curtos intervalos de tempo, os dados das imagens obtidas na faixa do termal podem variar temporalmente (BAPTISTA, 2012).

Amorim (2018) demonstrou que no período diurno a variabilidade espacial da temperatura da superfície está relacionada com as condições atmosféricas no período que antecede a tomada da imagem, sendo as maiores diferenças entre as áreas construídas e não construídas registradas no período chuvoso.

Isso ocorre porque, no período com os menores totais de precipitação, a vegetação fica menos exuberante e comparando-se uma área vegetada com diversos tipos de cobertura da terra no intraurbano e em outros pontos rurais menos vegetados, os gradientes entre o urbano e o rural diminuem, ou seja, as temperaturas da superfície do ambiente rural se aproximam das temperaturas urbanas. Assim, não é porque a cidade ficou mais "fresca" e sim porque o campo ficou mais quente devido à diminuição da biomassa (Figura 3).

Conforme demonstrou Amorim (2018) nos períodos com os maiores totais de precipitação, a vegetação fica com as folhas mais desenvolvidas e há maior umidade no solo, fazendo com que, comparativamente, as temperaturas superficiais nessas áreas sejam menores do que nos ambientes construídos.

Assim, comparando-se as intensidades das temperaturas do ar (Figura 1) com as dos alvos (Figura 3) no dia em análise, os resultados mostraram que os gradientes das temperaturas da superfície (ilhas de calor superficiais) não foram tão elevados quando se compara o intraurbano e o entorno rural próximo. Entretanto, nos mapas da Figura 1, verifica-se que, no período noturno, as temperaturas do ar se apresentaram com diferenças elevadas entre o rural e o urbano.

Isto ocorre porque, durante a noite, as superfícies liberam o calor acumulado durante o dia e aquecem o ar havendo, portanto, o registro de fortes magnitudes das ilhas de calor atmosféricas nas áreas construídas. No dia em análise (08/06/2015) tal intensidade atingiu $7^{\circ} \mathrm{C}$. A carência de biomassa na estação seca e a baixa umidade do ar proporcionam no ambiente rural, a perda do calor superficial mais rapidamente para os níveis superiores da atmosfera quando se compara com as áreas construídas, resultando na diminuição da temperatura do ar no rural e o aumento da temperatura do ar nas áreas construídas, intensificando a ilha de calor atmosférica urbana. Em estudo realizado no Japão, Kawashima et al. (2000) mostrou que os coeficientes de correlação entre a temperatura do ar e a temperatura da superfície eram relativamente altos no período noturno, sendo que a temperatura da superfície sozinha explicou $80 \%$ da variação observada na temperatura do ar.

Embora não se tenha para Presidente Prudente imagens de satélites das temperaturas superficiais no período noturno, sabe-se que elas tendem a ser parecidas com as temperaturas do ar, fato que não ocorre durante o dia, quando as temperaturas dos alvos são, habitualmente, maiores do que as temperaturas do ar no mesmo instante, conforme demonstrou Amorim (2014). As superfícies cobertas com vegetação (arbórea e rasteira) tendem a se manter 
frescas sob o sol, contribuindo para manter a temperatura igual ou inferior à temperatura do ar, particularmente quando hidratadas.

Em revisão da literatura realizada por Arnfield (2003) sobre as duas décadas de investigação sobre clima urbano, verificou-se que embora as temperaturas de superfície apresentem alguns padrões espaciais e temporais semelhantes àquelas para as temperaturas do ar, esta correspondência não é exata, assim como se observou na presente pesquisa, nos horários próximos a passagem do satélite ( $9 \mathrm{~h}$ e $12 \mathrm{~h}$ ).

A temperatura dos alvos possui uma causalidade mais simples do que temperatura do ar. Mutiibwa et al. (2015) mostraram que há forte relação entre a temperatura da superfície e a temperatura do ar próxima à superfície, embora as duas temperaturas tenham significado físico e respostas às condições atmosféricas diferentes, conforme também se observou na presente pesquisa.

Deste modo, no período da manhã, as ilhas de calor de superfície obtidas por meio do sensoriamento remoto registradas às $10 \mathrm{~h} 22$ (hora local da passagem do satélite Landsat 8 ) foram mais fortes e apresentaram maior variabilidade espacial do que as ilhas de calor atmosféricas em horários próximos a tomada da imagem ( $9 \mathrm{~h}$ e $12 \mathrm{~h}$ ).

Estas diferenças entre as características das ilhas de calor de superfície e atmosférica, neste horário, têm a sua origem na natureza da superfície urbana "vista" pelo sensor do satélite. Neste caso, as temperaturas dizem respeito aos diferentes tipos de telhados, as copas das árvores, as estradas, sem que se tenham informações sobre as superfícies verticais. 


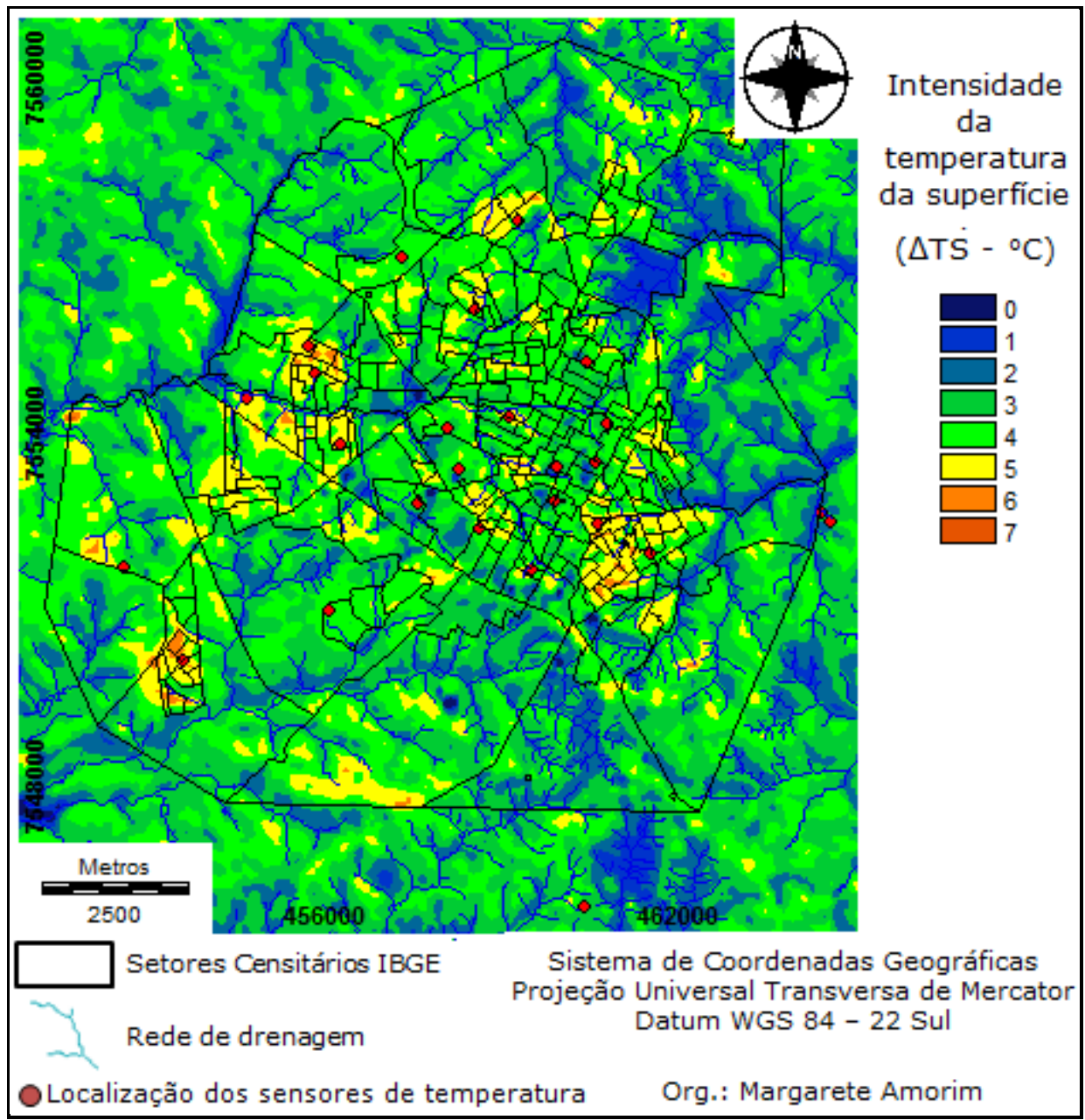

Figura 3 - Presidente Prudente: distribuição espacial da intensidade das ilhas de calor superficiais em 08/06/2015

\section{ANÁLISE TEMPORAL DA INTENSIDADE HORÁRIA DAS ILHAS DE CALOR DA ATMOSFERA INFERIOR NAS DIFERENTES ESTAÇÕES DO ANO}

Para se avaliar a intensidade e a manutenção horária das ilhas de calor atmosféricas próximas da superfície nos diferentes meses do ano, buscou-se no trabalho de Amorim e Dubreuil (2017), um exemplo de Presidente Prudente, no ano de 2016.

Neste trabalho foram realizados registros da temperatura do ar por meio de datalogger (U23-002) da marca HOBO, protegido por abrigo da mesma marca do tipo RS3, instalados em uma área densamente construída do ambiente urbano e em outra representativa do ambiente rural. No entorno do ponto rural de Presidente Prudente, localizado a leste da malha urbana, onde foi instalado o sensor de temperatura, há presença de vegetação rasteira e arbórea. A altitude do sensor foi de $415 \mathrm{~m}$ sobre o nível do mar. No ambiente urbano, o sensor foi instalado em área com alta densidade construtiva e média densidade de vegetação arbórea no centro-oeste da malha urbana, em altitude de $424 \mathrm{~m}$ sobre o nível do mar (Amorim e Dubreuil, 2017). 
Os sensores foram programados para registrarem a temperatura do ar a cada 10 minutos, para que no final de uma hora se tivesse a temperatura média, máxima e mínima do horário. Foram utilizados os valores médios horários mensais registrados no decorrer do ano de 2016 e processou-se o cálculo da intensidade das ilhas de calor, subtraindo-se os valores registrados nos ambientes urbanos dos registrados no ambiente rural ( $\Delta \mathrm{Tu}-r$ ).

A figura 4 tem o objetivo de evidenciar a variabilidade mensal e diurna da intensidade da ICU e inspirada na análise rítmica do Monteiro (1971), buscou-se mostrar o ritmo diurno da ICU e as mudanças ao longo do ano em função das condições sinóticas e dos tipos de tempo predominantes em cada período do ano. Com este propósito, inseriram-se na parte inferior da figura 4 informações sobre a diferença de temperatura média, a anomalia da precipitação e os totais de precipitação de cada mês, em relação às médias históricas (AMORIM E DUBREUIL, 2017).

$\mathrm{Na}$ figura 4 verifica-se que as maiores intensidades das ilhas de calor ocorreram, predominantemente, no período noturno, especialmente nos meses com os menores totais de precipitação (abril, julho, agosto e setembro).

As intensidades das ICU ultrapassaram os $6^{\circ} \mathrm{C}$ no período noturno nos meses mais secos e foram menores (abaixo de $2^{\circ} \mathrm{C}$ ) durante o dia (entre $10 \mathrm{~h}$ e $18 \mathrm{~h})$.

No verão, quando são registradas temperaturas elevadas na região e os maiores totais de precipitação, especialmente nos meses de janeiro, fevereiro e dezembro de 2016, as intensidades das ICU nos horários diurnos, foram maiores do que nos horários noturnos. Este fato proporciona para os moradores, situações de estresse térmico ainda maior, já que durante o dia, no ambiente tropical continental, as temperaturas são naturalmente elevadas e as ilhas de calor diurnas intensificam essa condição.

Pela proximidade ao trópico de Capricórnio (220 $07^{\prime}$ de latitude Sul), o clima de Presidente Prudente caracteriza-se por duas estações do ano bem definidas: um verão quente e chuvoso de outubro a março e um inverno ameno e seco de abril a setembro (BARRIOS e SANT'ANNA NETO, 1996). Nesta cidade os sistemas tropicais prevalecem na região a maior parte do ano, ora com o seu ramo atlântico, mais úmido, ora com trajetórias continentais, mais quentes e secas. Conforme exposto por Amorim et al. (2009), no período de primavera e verão, as temperaturas diárias oscilam entre os $20^{\circ} \mathrm{C}$ e $32^{\circ} \mathrm{C}$, com máximas absolutas próximas aos $40{ }^{\circ} \mathrm{C}$. Nesta época do ano concentra-se cerca de $75 \%$ da precipitação anual de $1.300 \mathrm{~mm}$. No outono/inverno as temperaturas decrescem ligeiramente, mas permanecem elevadas, à exceção dos episódios das invasões do anticiclone polar, quando as temperaturas mínimas oscilam entre $15^{\circ} \mathrm{C}$ e $20^{\circ} \mathrm{C}$, com valores absolutos que podem chegar a $0{ }^{\circ} \mathrm{C}\left(-1,8^{\circ} \mathrm{C}\right.$ em julho de 1975), segundo os dados registrados na Estação Meteorológica de Presidente Prudente, localizada na Faculdade de Ciências e Tecnologia da Universidade Estadual Paulista. 


\begin{tabular}{|c|c|c|c|c|c|c|c|c|c|c|c|c|}
\hline \multicolumn{13}{|c|}{2016} \\
\hline Hour & J & $\mathbf{F}$ & $M$ & A & M & J & J & A & $\mathrm{s}$ & 0 & $\mathrm{~N}$ & D \\
\hline $0: 00$ & 1.5 & 2.0 & 3.0 & 5.7 & 2.2 & 2.9 & 6.4 & 3.8 & 3.8 & 2.5 & 2.8 & 1.8 \\
\hline $1: 00$ & 1.3 & 1.9 & 2.8 & 5.5 & 2.1 & 2.9 & 6.2 & 3.7 & 3.7 & 2.3 & 2.7 & 1.8 \\
\hline $2: 00$ & 1.3 & 1.7 & 2.6 & 5.3 & 2.1 & 2.9 & 6.3 & 3.7 & 3.4 & 2.3 & 2.8 & 1.7 \\
\hline $3: 00$ & 1.3 & 1.6 & 2.6 & 5.2 & 2.0 & 2.8 & 5.9 & 3.6 & 3.3 & 2.1 & 2.8 & 1.7 \\
\hline $4: 00$ & 1.2 & 1.6 & 2.4 & 5.1 & 1.9 & 2.8 & 5.6 & 3.7 & 3.2 & 2.0 & 2.8 & 1.8 \\
\hline 5:00 & 1.1 & 1.6 & 2.3 & 5.1 & 2.0 & 2.8 & 5.5 & 3.7 & 3.0 & 2.0 & 2.8 & 1.8 \\
\hline 6:00 & 1.1 & 1.6 & 2.2 & 5.1 & 1.8 & 2.6 & 5.2 & 3.8 & 2.9 & 2.0 & 2.5 & 1.8 \\
\hline 7:00 & 0.9 & 1.5 & 2.1 & 4.6 & 1.7 & 2.7 & 5.1 & 3.5 & 2.1 & 1.4 & 1.8 & 1.4 \\
\hline $8: 00$ & 1.5 & 1.8 & 2.3 & 3.5 & 1.4 & 2.5 & 4.3 & 3.1 & 1.7 & 1.3 & 2.0 & 1.8 \\
\hline 9:00 & 1.8 & 2.2 & 2.3 & 2.0 & 1.0 & 1.6 & 1.9 & 1.8 & 1.1 & 1.3 & 2.1 & 1.9 \\
\hline $10: 00$ & 2.1 & 2.7 & 2.4 & 1.7 & 0.9 & 1.3 & 1.3 & 1.5 & 0.9 & 1.4 & 2.2 & 2.3 \\
\hline $11: 00$ & 2.4 & 2.7 & 2.6 & 1.8 & 0.8 & 0.7 & 0.7 & 1.2 & 1.0 & 1.6 & 2.1 & 2.4 \\
\hline $12: 00$ & 2.5 & 2.8 & 2.8 & 1.8 & 0.6 & 0.4 & 0.1 & 0.8 & 1.1 & 1.7 & 2.2 & 2.5 \\
\hline $13: 00$ & 2.6 & 3.0 & 2.8 & 1.9 & 1.0 & 0.4 & 0.3 & 0.9 & 1.2 & 1.9 & 2.1 & 2.7 \\
\hline $14: 00$ & 2.4 & 2.8 & 2.9 & 2.1 & 0.9 & 0.3 & 0.2 & 0.7 & 1.5 & 1.8 & 2.2 & 2.3 \\
\hline $15: 00$ & 2.4 & 2.9 & 3.0 & 2.4 & 0.9 & 0.3 & 0.2 & 0.4 & 1.6 & 2.0 & 1.8 & 2.1 \\
\hline $16: 00$ & 2.4 & 2.8 & 3.0 & 2.7 & 1.3 & 0.5 & 0.5 & 0.9 & 1.6 & 2.0 & 2.0 & 1.6 \\
\hline $17: 00$ & 2.2 & 2.4 & 3.0 & 3.0 & 1.3 & 1.3 & 1.5 & 1.2 & 1.5 & 1.7 & 1.7 & 1.3 \\
\hline $18: 00$ & 1.8 & 2.1 & 2.7 & 4.2 & 1.7 & 2.2 & 3.1 & 2.6 & 1.8 & 1.5 & 0.7 & 0.8 \\
\hline 19:00 & 1.6 & 2.2 & 3.0 & 5.3 & 2.0 & 2.7 & 4.6 & 3.7 & 3.3 & 2.4 & 1.8 & 1.1 \\
\hline 20:00 & 1.9 & 2.2 & 3.2 & 5.6 & 2.2 & 2.9 & 5.6 & 4.2 & 4.0 & 2.6 & 2.6 & 1.5 \\
\hline 21:00 & 1.9 & 2.2 & 3.3 & 5.8 & 2.4 & 3.1 & 6.0 & 4.0 & 4.0 & 2.7 & 2.7 & 1.9 \\
\hline 22:00 & 1.8 & 2.1 & 3.3 & 6.0 & 2.2 & 3.1 & 6.3 & 3.9 & 3.6 & 2.8 & 2.8 & 1.9 \\
\hline 23:00 & 1.7 & 2.1 & 3.2 & 5.9 & 2.1 & 3.2 & 6.3 & 3.9 & 3.5 & 2.6 & 2.9 & 1.7 \\
\hline Mean & 1.8 & 2.2 & 2.7 & 4.1 & 1.6 & 2.0 & 3.7 & 2.7 & 2.5 & 2.0 & 2.3 & 1.8 \\
\hline \multicolumn{13}{|c|}{ Temperature deviation from the $1981-2010$ average in ${ }^{\circ} \mathrm{C}$ (Presidente Prudente) } \\
\hline Dt $\left({ }^{\circ} \mathrm{C}\right)$ & 0.0 & 0.3 & -0.1 & 2.1 & -1.3 & -2.1 & 0.3 & -0.3 & -1.4 & -0.6 & 0.3 & -0.2 \\
\hline \multicolumn{13}{|c|}{ Rainfall deviation from the 1981-2010 average in \% (Presidente Prudente) } \\
\hline Dp (\%) & -18 & 65 & -31 & 21 & 50 & 31 & -55 & 120 & -35 & -35 & -65 & 18 \\
\hline \multicolumn{13}{|c|}{ Monthly rainfall (mm) in 2016} \\
\hline 2016 & 189.3 & 273.6 & 92.2 & 91.0 & 122.9 & 62.6 & 17.2 & 94.2 & 52.0 & 75.6 & 46.2 & 204.6 \\
\hline
\end{tabular}

Figura 4 - Média horária da intensidade da ilha de calor urbana atmosférica em Presidente Prudente no período de janeiro a dezembro de 2016 - diferença de temperatura entre o centro e o rural. Fonte: Amorim e Dubreuil (2017, p. 9).

Outra forma importante para se representar e analisar as intensidades das ilhas de calor no decorrer do dia, levando-se em consideração não os valores médios, mas as intensidades dos valores absolutos registrados em diferentes pontos do intraurbano e rural próximo são os painéis espaçotemporais (Figura 5). Associado aos gráficos de análise rítmica, tais painéis possibilitam a compreensão da interferência das características da atmosfera na 
intensidade e na magnitude das ilhas de calor ou mesmo das ilhas de frescor ${ }^{5}$ nos diferentes períodos do dia (AMORIM, 2017).

Para mostrar a representatividade da intensidade das ilhas de calor atmosférica no dia utilizado como exemplo da evolução diária da ilha de calor no item anterior (08/06/2015), a figura 5 evidencia nos painéis espaço-temporais o padrão da intensidade da ilha de calor estabelecido no mês de junho de 2015, nos horários de menor e de maior intensidade da ICU (12h e $21 \mathrm{~h}$ ).

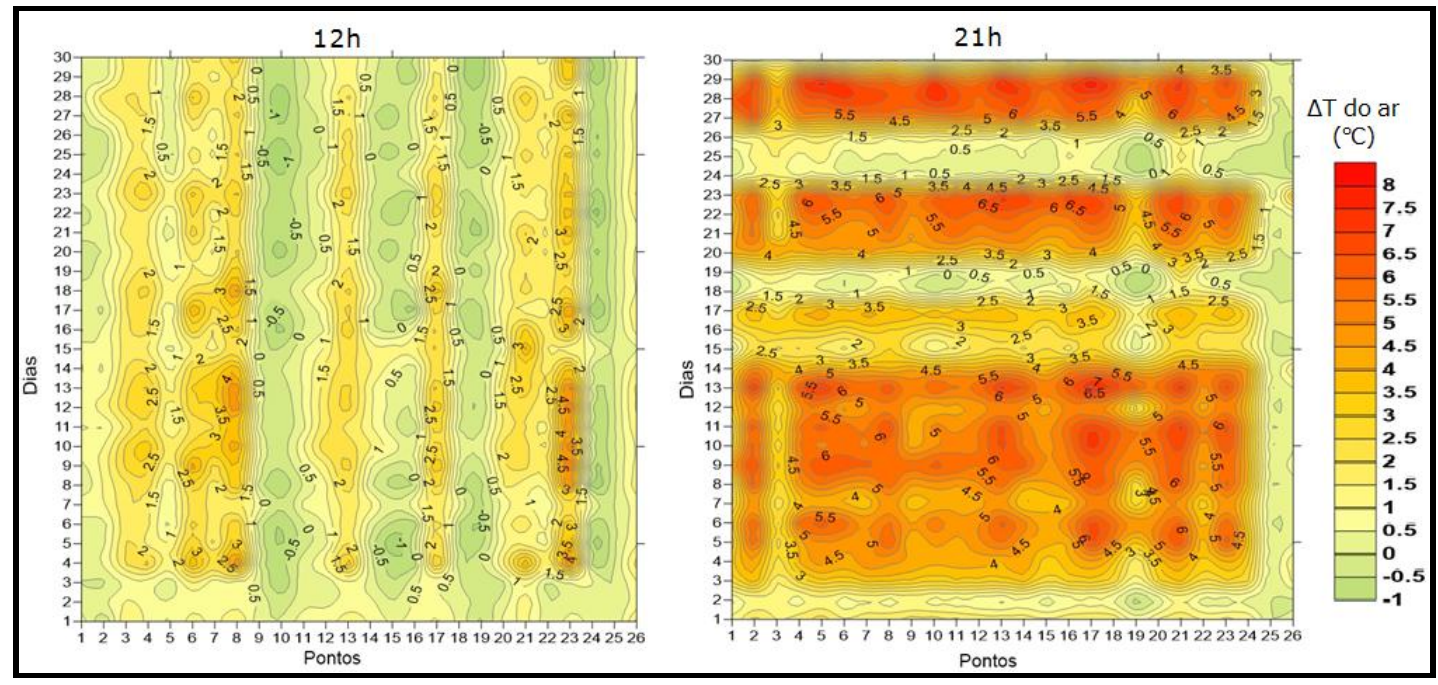

Figura 5 - Variação espaço-temporal das diferenças da temperatura do ar em 26 pontos de Presidente Prudente em relação ao ambiente rural (ponto 25 da figura 2) no mês de junho de 2015

\section{CONSIDERAÇÕES FINAIS}

Neste texto buscou-se, por meio de alguns exemplos, mostrar os avanços do conhecimento na climatologia urbana, principalmente quando se trata da geração das ilhas de calor nas suas diferentes formas de manifestações e representações.

Diversos estudos realizados no Brasil em cidades de pequeno e médio porte ${ }^{6}$ mostraram que não há dúvidas de que tais cidades possuem especificidades climáticas que devem ser consideradas, e estas variam de intensidade de acordo com suas características próprias, com diferentes possibilidades de combinações.

Neste sentido, acredita-se que além da atenção que o estudo do clima urbano e das ilhas de calor recebe nas metrópoles pelos organismos

\footnotetext{
${ }^{5}$ Ilha de frescor foi conceito utilizado por Mendonça (1994), Steinecke (1999) e Amorim (2000), quando as diferenças entre as temperaturas do ar de áreas urbanas e rurais foram menores do que zero $(\Delta T u-r)$. Oke (1978) denominou essas alterações negativas de "efeito parque".

${ }^{6}$ Exemplos de trabalhos desenvolvidos no Brasil em cidades de pequeno e médio porte: Tarifa, 1977; Sartori, 1979; Tavares, 1997; Vecchia, 1997; Fonzar, 1981; Mendonça, 1994; Santos, 1996; Sette, 1996; Pitton, 1997; Cruz, 2009; Ugeda Jr., 2012; Minaki, 2014; Cardoso, 2015; Fante, 2014; Rampazzo, 2015; Teixeira, 2015; Porangaba, 2015; Cardoso, 2015; Dorigon, 2015; Mendonça, 2015
}

Ano 15 - Edição Especial - XIII Simpósio Brasileiro de Climatologia Geográfica - JUN 2019 
internacionais $^{7}$ de pesquisa, as cidades de pequeno e médio porte também precisam ser consideradas nessas análises. Não apenas porque podem interferir além da escala local do clima, mas, principalmente, porque nelas habita grande parte das pessoas na escala nacional e planetária.

De fato, as alterações climáticas são sentidas e diagnosticadas, sobretudo na escala local e a variabilidade geográfica das ilhas de calor permitem análises da vulnerabilidade da população, que não sofre igualmente frente às intensidades detectadas.

Deste modo, há duas questões a serem enfrentadas: a primeira, diz respeito à necessidade das políticas públicas privilegiarem a escala local do clima para incrementarem sua eficácia no sentido de mitigar as ilhas de calor; a segunda é considerar os diferentes níveis de vulnerabilidade da população no intraurbano para que tais políticas sejam efetivas para os diferentes segmentos da sociedade.

As técnicas aqui apresentadas para a realização de pesquisas sobre as ilhas de calor em cidades de pequeno e médio porte evidenciam as avanços no sistema de registro e de análise da temperatura do ar, fundamentais para o diagnóstico das ilhas de calor.

O sensoriamento remoto e a modelagem das ilhas de calor atmosféricas permitem maior detalhamento das mesmas no intraurbano e rural próximo, podendo ser um instrumento fundamental para subsidiar medidas mitigadoras permitindo intervenções mais localizadas e quando representadas por meio das intensidades dos fenômenos e não apenas dos valores absolutos, possibilitam análises comparativas entre cidades e entre os diferentes sistemas atmosféricos nos dias de registros.

Além desses avanços, deve-se também destacar as análises da evolução e manutenção da magnitude e intensidade das ilhas de calor atmosféricas nos diferentes tipos de tempo.

O conhecimento da dinâmica da formação das ilhas de calor e a variação de suas intensidades sempre fez parte das nossas preocupações, no decorrer dos anos dedicados a essas pesquisas.

Além de quantificar as alterações detectadas, tem-se buscado realizar uma análise geográfica do fenômeno, estabelecendo relações entre os dados mensurados e os elementos componentes da cidade.

Medidas precisam ser tomadas para amenizar situações de desconforto térmico em vários períodos do ano, quando as temperaturas são naturalmente elevadas e são intensificadas pela geração das ilhas de calor urbanas. Desse modo, os estudos realizados (AMORIM, 2010, 2017) têm demonstrado a necessidade de um projeto de rearborização urbana com espécies adequadas ao ambiente tropical; a utilização de materiais construtivos adequados que não exijam a climatização dos ambientes internos; ao se implantar novos

\footnotetext{
${ }^{7}$ Os trabalhos sobre o Primeiro Relatório de Avaliação sobre Alterações Climáticas e Cidades (Arc3) publicados em 2011, teve o objetivo de construir a base científica para a ação nos ambientes urbanos sobre as alterações climáticas. Os estudos foram realizados em doze cidades, todas elas de grande porte (Atenas, Dakar, Delhi, Harare, Kingston, Londres, Melbourne, Nova York, São Paulo, Xangai, Tóquio e Toronto). Entretanto, as cidades de pequeno e médio porte não são mencionadas como produtoras de características climáticas específicas e que podem contribuir negativamente para a qualidade de vida de milhares de pessoas que nelas vivem.
}

Ano 15 - Edição Especial - XIII Simpósio Brasileiro de Climatologia Geográfica - JUN 2019 
loteamentos, as características climáticas devem ser consideradas, evitando-se a impermeabilização generalizada do solo e a edificação em toda a área do terreno, propiciando maior quantidade de áreas permeáveis no ambiente urbano.

O detalhamento das ilhas de calor possibilita o oferecimento de subsídios à gestão territorial e ao planejamento urbano, visando à sustentabilidade da sociedade, com o objetivo de contribuir para a tomada de decisões pensadas e planejadas com base no conhecimento detalhado do clima e levando em consideração os elementos ambientais para se evitar problemas para a qualidade de vida das pessoas.

Os estudos sobre as ilhas de calor, portanto, devem ser considerados nas análises sobre a qualidade ambiental urbana, para que seja possível a construção de cidades mais saudáveis para seus habitantes, especialmente aos menos favorecidos economicamente e, portanto, mais vulneráveis ao desconforto térmico.

\section{AGRADECIMENTOS}

À Fundação de Amparo à Pesquisa do Estado de São Paulo (FAPESP) pelo financiamento de projeto de Auxílio à pesquisa (2014/16350-3) e Acordo de Cooperação FAPESP/CNRS (2015/50439-4). Ao CNPq - Bolsa de Produtividade em Pesquisa - processo: 307287/2014-9.

\section{REFERÊNCIAS BIBLIOGRÁFICAS}

AL MANNE, S. A. Influência do uso e ocupação do solo na formação de ilhas de calor em Uberaba-MG. 2014. 51f. Dissertação (Mestrado em Inovação Tecnológica) - Programa de Mestrado Profissional em Inovação Tecnológica, Universidade Federal do Triângulo Mineiro, Uberaba.

AMORIM, M. C. C. T. O clima urbano de Presidente Prudente/SP. 2000. 374f. Tese (Doutorado em Geografia) - Faculdade de Filosofia, Letras e Ciências Humanas, Universidade de São Paulo, São Paulo.

AMORIM, M. C. C. T. Intensidade e forma da ilha de calor urbana em Presidente Prudente/SP. Geosul (UFSC), v. 20, p. 65-82, 2005.

AMORIM, M. C. C. T. Climatologia e gestão do espaço urbano. Mercator, número especial, p. 71-90, dez. 2010.

AMORIM, M. C. C. T. As temperaturas da superfície e do ar: contribuições aos estudos de clima urbano. In: X Simpósio Brasileiro de Climatologia Geográfica; V Simpósio Paranaense de Climatologia, Reunião da COC-UGI, 2014, Curitiba. Anais... Curitiba: UFPR, 2014. p. 1122-1130.

AMORIM, M. C. C. T. Teoria e método para estudo das ilhas de calor em cidades tropicais de pequeno e médio porte. 2017. 178f. (Tese de Livre docência) Faculdade de Ciências e Tecnologia, Universidade Estadual Paulista, Presidente Prudente-SP.

AMORIM, M. C. C. T. Spatial variability and intensity frequency of surface heat island in a Brazilian city with continental tropical climate through remote 
sensing. Remote Sensing Applications: Society and Environment, v. 9, p. 10-16, 2018.

AMORIM, M. C. C. T.; DUBREUIL, V. Intensity of Urban Heat Islands in Tropical and Temperate Climates. Climate. , v.5, p.91 - 104, 2017.

AMORIM, M. C. C. T.; DUBREUIL, V.; CARDOSO, R. S. Modelagem espacial da ilha de calor urbana em Presidente Prudente (SP) Brasil. Rev. Brasileira de Climatologia, v. 16, p. 29-45, 2015.

AMORIM, M. C. C. T.; DUBREUIL, V.; QUENOL, H.; SANT'ANNA, J. L. Características das ilhas de calor em cidades de porte médio: exemplos de Presidente Prudente (Brasil) e Rennes (França). Confins [Online], v. 7. p. 1-16, 2009. Disponível em: <http://confins.revues.org/index6070.html>. Acesso em: 06 set. 2013.

ARNFIELD, A. J. Two decades of urban climate research: a review of turbulence, exchanges of energy and water, and the urban heat island. International Journal of Climatology, v. 23, n. 01, p. 1-26, 2003.

ASSIS, E. S. Mecanismos de desenho urbano apropriados à atenuação da ilha de calor urbana: análise de desempenho de áreas verdes em clima tropical. 1990. 168f. Dissertação (Mestrado em Arquitetura), Faculdade de Arquitetura e Urbanismo, Universidade Federal do Rio de Janeiro, Rio de Janeiro.

BAPTISTA, Gustavo Macedo de Mello. Sensores Imageadores na Faixa Termal (8 - $14 \mu \mathrm{m}$ ). In: Paulo Roberto Meneses; Tati de Almeida. (Org.). Introdução ao Processamento de Imagens de Sensoriamento Remoto. Brasília: UnB/CNPq, v. 1, p. 47-56, 2012.

BARRIOS, N. A. Z.; SANT'ANNA NETO, J. L. A circulação atmosférica no extremo oeste paulista. Boletim climatológico, Presidente Prudente, v.1, n.1, p.8-9, março 1996.

BRANDÃO, A. M. de P. M. O clima urbano da cidade do Rio de Janeiro. 1996. 362f. Tese (Doutorado em Geografia Física) - Faculdade de Filosofia Letras e Ciências Humanas, Universidade de São Paulo, São Paulo.

BRYSON, R. A.; ROSS, J. E. The climate of the city. Urbanization and environment, Belmont: Duxbury Press, 1972.

CARDOSO, R. S. Classificação de potenciais unidades climáticas em Presidente Prudente-SP. 2015. 137f. Dissertação (Mestrado em Geografia) - Universidade Estadual Paulista Júlio de Mesquita Filho, Presidente Prudente.

CHANDLER, T. J. The climate of London. London: Hutchison of London, 1965. $287 p$.

DANNI-OLIVEIRA, I. M. Aspectos temporo-espaciais da temperatura e umidade relativa de Porto Alegre em Janeiro de 1982: contribuição ao estudo do clima urbano. 1987. 129f. Dissertação (Mestrado em Geografia Física) - Faculdade de Filosofia, Letras e Ciências Humanas, Universidade de São Paulo, São Paulo.

DORIGON, L. P. Clima urbano em Paranavaí/PR: análise do espaço intraurbano. 2015. 121f. Dissertação (Mestrado em Geografia) - Universidade Estadual Paulista Júlio de Mesquita Filho, Presidente Prudente. 
DUBREUIL, V.; AMORIM, M. C. C. T.; FROISSARD, X.; QUENOL, H. Métodos e monitoramento da variabilidade espaçotemporal da ilha de calor em cidades de porte médio - Rennes/França e Presidente Prudente/Brasil. SILVA, C. A. (Org.); FIALHO, E. S. (Org.); STEINKE, E. T. (Org.). Experimentos em Climatologia Geográfica. 1a. ed. Dourados (MS): Editora da UFGD, 2014. p. 23-32.

FANTE, K. Variabilidade da temperatura em áreas urbanas não metropolitanas do Estado de São Paulo - Brasil no período de 1961 - 2011. 2014. 254f. Dissertação (Mestrado em Geografia) - Universidade Estadual Paulista Júlio de Mesquita Filho, Presidente Prudente.

FERNÁNDEZ GARCÍA, F. Manual de climatologia aplicada: clima, medio ambiente y planificación. Madrid: Editorial síntesis, S.A., 1996. 285p.

FOISSARD, X. L'îlot de chaleur urbain et le changement climatique: application à I'agglomération rennaise. These (Docteur) - Université de Rennes II, Rennes, 2015.

FOISSARD, X.; QUENOL, H.; DUBREUIL, V. Analyse et spatialisation de I'ilot de chaleur urbain dans I'agglomération rennaise.. In: 26E Colloque de I'AIC, 2013, Cotonou. Actes du 26e colloque de I'AIC. Cotonou: AIC, 2013. p. 242-247.

FONZAR, B. C. O processo de ocupação regional. O modelo urbano e o conforto térmico da Alta Sorocabana: um teste aplicado a Presidente Prudente. 1981. 156f. Dissertação (Mestrado em Geografia Física) - Faculdade de Filosofia, Letras e Ciências Humanas, Universidade de São Paulo, São Paulo.

GARTLAND, L. Ilhas de Calor: como mitigar zonas de calor em áreas urbanas. São Paulo: Oficina de textos, 2010.

GOMES, W. P.; AMORIM, M. C. C. T.; DUBREUIL, V. Modelagem da Ilha de Calor Urbana Aplicada ao Ambiente Litorâneo - Ubatuba/Brasil. Revista do Departamento de Geografia, v. 34, p. 82-94, 2017.

KAWASHIMA, S.; MIWA, T.; ISHIDA, T.; MINOMURA, M. Relations between surface temperature and air temperature on a local scale during winter nights. Journal of Applied Meteorology, v. 39, n. 9, p. 1570-1579 September 2000.

LANDSBERG, H. E. Meteorological observations in urban areas. Meteorological Monographs, v. 11, n. 33, p. 91-99, October 1970.

LANDSBERG, M. E. The urban climate. New York: Academia Press, 1981. 276p.

LOMBARDO, M. A. Ilha de calor nas metrópoles: o exemplo de São Paulo. São Paulo: Hucitec, 1985. 244p.

LOWRY, W. P. Empirical estimation of urban effects on climat: a problem analysis. Journal of applied meteorology, v. 16, p. 129-135, fev. 1977.

MAITELLI, G. T. Uma abordagem tridimensional de clima urbano em área tropical continental: o exemplo de Cuiabá-MT. 1994. 204f. Tese (Doutorado em Geografia Física) - Faculdade de Filosofia, Letras e Ciências Humanas, Universidade de São Paulo, São Paulo.

MENDONÇA, F. de A. O clima e o planejamento urbano de cidade de porte médio e pequeno: proposição metodológica para estudo e aplicação à cidade de Londrina, PR. 1994. 322f. Tese (Doutorado em Geografia Física) - Faculdade de Filosofia, Letras e Ciências Humanas, Universidade de São Paulo, São Paulo. 
MENDONCA F.; DUBREUIL V. Termografia de superfície e temperatura do ar na RMC (Região Metropolitana de Curitiba - PR). Revista RA'E GA - O espaço geográfico em análise, n.9, p.25-35, 2005.

MENDONÇA, V. M. Clima urbano de Londrina/PR. 2015. 201f. Dissertação (Mestrado em Geografia) - Universidade Estadual Paulista Júlio de Mesquita Filho, Presidente Prudente.

MINAKI, C. O clima urbano como indicador de qualidade ambiental: estudo de caso da paisagem urbana de Araçatuba/SP. 2014. 266f. Tese (Doutorado em Geografia) - Universidade Estadual Paulista Júlio de Mesquita Filho, Presidente Prudente.

MONTEIRO, A. O clima urbano do Porto: contribuição para a definição das estratégias de planejamento e ordenamento do território. Fundação Calouste Gulbenkian, Junta Nacional de Investigação Científica e Tecnológica, 1997. $485 p$.

MONTEIRO, C. A. de F. Análise rítmica em climatologia. Climatologia. São Paulo: USP/IGEOG, n. 1, 1971.

MONTEIRO, C. A. de F. Teoria e Clima Urbano. São Paulo: IGEOG/USP, 1976. 181p. (Série Teses e Monografias, 25).

MOTTA, D.; MATA, D. Crescimento das cidades médias. Boletim Regional e Urbano, Brasília, n. 1, p. 33-38, dez. 2008.

MUTIIBWA, D.; STRACHAN, S.; ALBRIGHT, T. Land Surface Temperature and Surface Air Temperature in Complex Terrain. IEEE Journal of Selected Topics in Applied Earth Observations and Remote Sensing, v. 8, n. 10, p. 4762-4774, Oct. 2015.

NAKATA-OSAKI, C. M.; SOUZA, L. C. L. de; RODRIGUES, D. S. Impacto da geometria do cânion urbano na intensidade de ilha de calor noturna: análise através de um modelo simplificado adaptado a um SIG. Ambiente Construído, Porto Alegre, v. 16, n. 3, p. 73-87, jul./set. 2016.

OKE, T. R. Boundary Layer Climates. London: Methuem \& Ltd. A. Halsted Press Book, John Wiley \& Sons, New York, 1978. 372p.

OKE, T. R. The energetic basis of the urban heat island. Quarterly Journal of the Royal Meteorological Society, v. 108, n. 455, p. 1-24, jan. 1982.

OKE, T. R.; MILLS, G.; CHRISTEN, A.; VOOGT, J. Urban Heat Island. In Urban Climates (pp.). Cambridge: Cambridge University Press, p.197-237, 2017.

PITTON, S. E. C. As cidades como indicadores de alterações térmicas. São Paulo, 1997. 272p. Tese (Doutorado em Geografia Física) - Faculdade de Filosofia, Letras e Ciências Humanas, Universidade de São Paulo.

PORANGABA, G. F. O. O clima urbano das cidades do interior do estado de São Paulo: uma análise do campo térmico de Assis, Cândido Mota, Maracaí e Tarumã. 2015. 345f. Tese (Doutorado em Geografia) - Universidade Estadual Paulista Júlio de Mesquita Filho, Presidente Prudente.

PORANGABA, G. F. O. ; TEIXEIRA, D. C. F.; AMORIM, M. C. C. T. Procedimentos metodológicos para análise das ilhas de calor em cidades de pequeno e médio porte. Revista Brasileira de Climatologia, v. 21, p. 225-247, 2017. 
RAMPAZZO, C. R. O clima urbano em Alfredo Marcondes - SP: uma análise dos indicadores geoambientais. 2012. 220f. Trabalho de Conclusão de Curso. (Graduação em Geografia) - Universidade Estadual Paulista Júlio de Mesquita Filho, Presidente Prudente.

RAMPAZZO, C. R. Clima e Produção do espaço urbano: contribuição ao estudo da geografia do clima no contexto das cidades de São Carlos e Marília (SP). 2015. 304f. Dissertação (Mestrado em Geografia) - Universidade Estadual Paulista Júlio de Mesquita Filho, Presidente Prudente.

ROSENZWEIG, C.; SOLECKI, W. D.; HAMMER, S. A.; MEHROTRA, S. Urban Climate Change in Context. Climate Change and Cities: First Assessment Report of the Urban Climate Change Research Network, Eds., Cambridge University Press, Cambridge, UK, 43-81, 2011.

SAMPAIO, A. H. L. Correlações entre uso do solo e ilha de calor no ambiente urbano: o caso de Salvador. 1981. 103f. Dissertação (Mestrado em Geografia Física) - Faculdade de Filosofia, Letras e Ciências Humanas, Universidade de São Paulo, São Paulo.

SANT'ANNA NETO, J. L. Desafios da climatologia geográfica no Brasil: da competência técnica ao compromisso social. In: SILVA, C. A.; FIALHO, E. S. (Org.). Concepções e Ensaios da Climatologia Geográfica. 1ed. Dourados: Editora da UFGD, 2012, v. 1, p. 13-38.

SANTOS, J. W. M. C. O clima urbano de Maringá: ensaio metodológico para cidades de porte médio e pequeno. 1996. 172f. Dissertação (Mestrado em Geografia Física) - Faculdade de Filosofia, Letras e Ciências Humanas, Universidade de São Paulo, São Paulo.

SARTORI, M. G. B. O clima de Santa Maria, RS: do regional do urbano. 1979. 166f. Dissertação (Mestrado em Geografia Física) - Faculdade de Filosofia, Letras e Ciências Humanas, Universidade de São Paulo, São Paulo.

SETTE, D. M. O clima urbano de Rondonópolis-MT. 1996. 137f. Dissertação (Mestrado em Geografia Física) - Faculdade de Filosofia, Letras e Ciências Humanas, Universidade de São Paulo, São Paulo.

SOUZA, L. C. L. de. Influência da geometria urbana na temperatura do ar ao nível do pedestre. São Carlos, 1996. 125p. Tese (Doutorado em Ciências da Engenharia Ambiental) - Escola de Engenharia de São Carlos, Universidade de São Paulo, São Carlos.

SOUZA, L. C. L. DE; TENTE, C. M.; GIUNTA, M. B.; NAKATA, C. M. Fator de visão do céu e intensidade de ilhas de calor na escala do pedestre. Ambiente Construído, Porto Alegre, v. 10, n. 4, p. 155-167, out./dez. 2010.

TARIFA, J. R. Análise comparativa da temperatura e umidade na área urbana e rural de São José dos Campos (SP). Geografia, v. 2, n. 4, p. 59-80, outubro 1977.

TAVARES, R. O clima local de Sorocaba (SP): tendências e análise comparativa cidade-campo. São Paulo, 1997. 205f. Dissertação (Mestrado em Geografia Física) - Faculdade de Filosofia, Letras e Ciências Humanas, Universidade de São Paulo. 
TEIXEIRA, D. C. F. O clima urbano de Rancharia - SP. 2015. 217f. Dissertação (Mestrado em Geografia) - Universidade Estadual Paulista Júlio de Mesquita Filho, Presidente Prudente.

TEIXEIRA, D. C. F.; AMORIM, M. C. C. T. Ilhas de calor: representações espaciais de cidades de pequeno porte por meio de modelagem. GEOUSP (USP), v. 21, p. 239-256, 2017.

UGEDA JÚNIOR, J. C. Clima urbano e planejamento na cidade de Jales-SP. 2012. 383f. Tese (Doutorado em Geografia) - Universidade Estadual Paulista Júlio de Mesquita Filho, Presidente Prudente.

VECCHIA, F. Clima e ambiente construído: a abordagem dinâmica aplicada ao conforto humano. 1997. 329f. Tese (Doutorado em Geografia Física) - Faculdade de Filosofia, Letras e Ciências Humanas, Universidade de São Paulo, São Paulo.

WENG, Q. Fractal analysis of satellite-detected urban heat island effect. Photogrammetric engineering \& remote sensing, v. 69, n. 5, p. 555-566, May 2003.

ZAMPARONI, C. A. P. G. Ilha de Calor em Barra do Bugres e Tangará da Serra MT: Uma Contribuição ao Estudo do Clima Urbano em Cidades de Pequeno Porte em Área Tropical. 1995. 116p. Dissertação (Mestrado em Geografia Física) Faculdade de Filosofia, Letras e Ciências Humanas, Universidade de São Paulo, São Paulo 